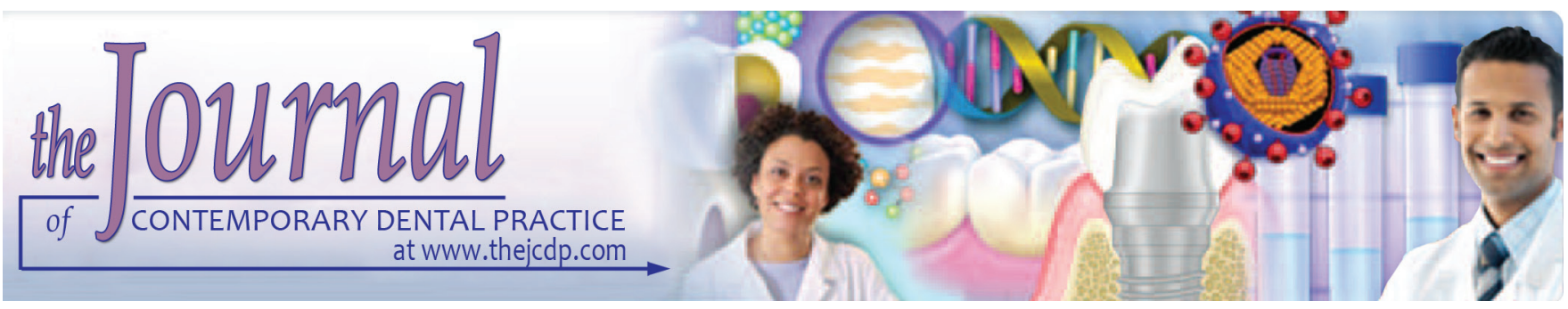

\title{
Early Childhood Caries: A Review
}

\author{
Abdulfatah Alazmah
}

\section{ABSTRACT}

Aim: To review and update the current knowledge about early childhood caries (ECC) and its etiology, prevalence, risk factors, management, and preventive strategies.

Background: Early childhood caries is a disease affecting significantly both well-developed and industrial nations. The ECC can significantly affect the child's quality of life, as it may lead to infection, swelling, pain, and other symptoms. The ECC affects children after eruption of primary teeth until age of around 5 years.

Review results: The ECC affects all parts of the tooth including the smooth surface. Upper anterior teeth and primary molars are usually affected. The lower anterior teeth are less likely affected. The risk factors for ECC are diet, bacteria, and host susceptibility. The additional factors, such as presence of enamel defect and the feeding practices also contribute to the initiation and progress of ECC.

Conclusion: Dentists must focus on utilizing existing techniques to distinguish indications of right on time and propelled caries and give guidance on the best way to counteract and control caries in children. Approaches should be directed to preventive caries control strategies among children.

Clinical significance: Preventing and controlling the development of ECC among children is important to maintain effective eating, speech development, and formation of a positive self-image.

Keywords: Children, Early childhood caries, Fluoride, Nursing caries, Pediatric dentistry.

How to cite this article: Alazmah A. Early Childhood Caries: A Review. J Contemp Dent Pract 2017;18(8):732-737.

Source of support: Nil

Conflict of interest: None

Department of Preventive Dental Sciences, College of Dentistry Prince Sattam Bin Abdulaziz University, Al Kharj, Kingdom of Saudi Arabia

Corresponding Author: Abdulfatah Alazmah, Department of Preventive Dental Sciences, College of Dentistry, Prince Sattam Bin Abdulaziz University, Al Kharj, Kingdom of Saudi Arabia e-mail: asaz.pedo@gmail.com

\section{INTRODUCTION}

The expression "dental caries" is utilized to represent the outcomes, signs, symptoms, and side effects of a localized chemical disintegration of the tooth surface (enamel and dentin) caused by dental plaque and mediated by saliva. ${ }^{1}$ Caries is considered as disease with high incidence among childhood chronic conditions, where it is also well-thought-out to cause harm on both population and individual well-being. ${ }^{2,3}$ When comparing it with other common diseases, dental caries is five times as frequent as asthma and seven times as common as hay fever. ${ }^{4}$

The American Academy of Pediatrics demonstrates that dental and oral infections keep on infecting children and, specifically, very young children. In primary teeth, dental caries is a preventable and reversible disease if treated in early stages, but when left untreated it will lead to pain, bacteremia, alteration in growth and development, premature tooth loss, speech disorder, increase in treatment costs, loss of confidence, and negatively affect successor permanent teeth. Dental caries in young children has a pattern; diverse terms and terminology have been utilized to express them. ${ }^{5}$ The definitions used previously to describe this bacterial disease were related to cause and the improper utilization of nursing bottle. These terms are used interchangeably: "Early childhood tooth decay", "early childhood caries (ECC)", "bottle caries", "nursing caries", "baby bottle tooth decay", or "night bottle mouth". ${ }^{6,7}$ The expression "ECC" was proposed more than 20 years ago during a workshop supported by the Centers for Disease Control and Prevention (CDC) trying to scope the consideration upon the various issues, such as financial, sociopsychological, and behavioral, which contributes to the formation of caries at such initial years, instead of attributing its manifestation solely on feeding bottles. ${ }^{8}$

In 1999, a primary definition was established by a workshop organized by the National Institute for Dental and Craniofacial Research following the conference on ECC that was held in 1997.5,9 Furthermore, in 2005, 
the American Academy of Pediatric Dentistry (AAPD) defined ECC as "the presence of one or more decayed (noncavitated or cavitated lesions), missing (because of caries), or filled tooth surfaces in any primary tooth in a child aged 71 months or younger". ${ }^{10}$ The term "Severe Early Childhood Caries (S-ECC)" refers to "atypical" or "progressive" or "acute" or "rampant" patterns of dental caries, where in their definition AAPD scored ECC as the following: "in children younger than 3 years of age, any sign of smooth-surface caries is indicative of S-ECC. From ages 3 through 5, 1 or more cavitated, missing (due to caries), or filled smooth surfaces in primary maxillary anterior teeth or a decayed, missing, or filled score of $\geq 4$ (age 3 ), $\geq 5$ (age 4 ), or $\geq 6$ (age 5 ) surfaces constitutes S-ECC." ${ }^{10}$ Subsequently, it is suggested that the expression "early childhood caries" is a best fit to reflect the multifactorial etiologic process, where also it can be utilized when representing any type of caries in infants and preschool children. ${ }^{11,12}$

\section{PREVALENCE}

Nevertheless, bearing in mind the prevalence of dental caries in youngsters in the Western courtiers, caries in children before school age remains an insistent problem. The ECC has become an epidemic that keeps on affecting infants and preschool children around the world. A comprehensive survey of the study of disease transmission of ECC demonstrated that its pervasiveness differs from populace to populace. Maxillary primary incisors and primary first molars are more susceptible to caries. Mandibular incisors are less affected by caries because they are more protected by the salivary secretion produced by both sublingual and submandibular glands in addition to the tongue cover. Both the tongue and saliva come from both submandibular and sublingual glands. ${ }^{1}$ A broad audit of caries affecting upper front teeth in kids, containing various reviews from Asia, Middle East, Africa, North America, and Europe found the most astounding caries pervasiveness in the eastern part of South Asia and Africa. ${ }^{13}$

In the United States, the CDC detailed that the predominance of dental decay between young children aged less than 2 years and not older than 5 years (between 2 and 5 years old) was $24.2 \%$ in 6 years between 1988 and 1994 and increased by about 3\% (27.9\%) between 1999 and 2004; this is according to the third National Health and Nutrition Examination Survey. ${ }^{14,15}$ In developing nations, the prevalence of ECC shows an estimate of 1 to $12 \%$ in infants, and this increases to reach $85 \%$ that has been accounted for disadvantaged groups. ${ }^{16-18}$ In the Western world, the pervasiveness at age 3 was about $20 \%$, and solid affiliations were discovered with ethnicity and financial ability. ${ }^{19}$ In the Japanese nationwide overview in $2007,2.8 \%$ of the children aged around 18 months experience ECC, while $25.9 \%$ of the kids aged 3 years experience the same condition in Japan. ${ }^{20}$

\section{ETIOLOGY}

Research has confirmed that ECC is a multifactorial disease. As any caries lesion, ECC is caused by poor oral hygiene, bacterial invasion, bad diet habits, etc. ${ }^{21,22}$ Also, the presence of enamel defects might contribute to the formation of lesion, such as hypoplasia, known as hypoplasia-associated severe early childhood caries. ${ }^{23}$ This type of decay influences generally young kids at or beneath levels of poverty, teeth which are usually vulnerable to caries have structural damage.

\section{RISK FACTORS}

There are several factors that contribute to the formation of ECC, some of which will be discussed in this review.

\section{Microbiological Risk Factors}

The ECC is a transmittable disease. Streptococcus mutans (SM) and Streptococcus sobrinus are the most widely recognized causative specialists. Lactobacilli additionally have a distinct role in the caries progression but not in its initiation. ${ }^{24}$

Studies have shown that there are two ways for SM transmission: Vertical and horizontal transmission. Vertical transmission is carried between caregiver and child (i.e., mother or father to child). ${ }^{25}$ Subsequently, poor maternal oral hygiene and higher sugar intake per day rise the chances of transferring the disease to the child by the mother. ${ }^{26}$ Whereas, for horizontal transmission, neonatal factors may increase the chance of acquiring SM. Infant delivery by cesarean section transmits SM earlier than through natural deliveries. ${ }^{27}$ The time of 13 to 16 months is roughly needed between SM colonization and caries lesion initiation and advancement.

\section{Dietary Risk Factors}

In addition to infection with SM bacteria, children who have high-sugared drinks also suffer from ECC. Sugar is processed by both SM and lactobacilli that will furthermore transform it into acid, which will cause demineralization of tooth structure. Evidence recommends that both cow's and human milk are considered to be less cariogenic than sucrose, with cow's milk being the least cariogenic. The cariogenic capability of newborn child equations fluctuated over the reviews, with some being as cariogenic as sucrose. On the contrary, the available evidence in the literature discussing the cariogenicity of 
breast milk is weak and lacks consistency, whereas the cariogenicity of milk formulas varies across studies. ${ }^{28,29}$ The best accessible data show that low level of caries in nations is associated with sugar utilization between 40 and 55 gm per person in 1 day. ${ }^{30}$ The connection among proper diet and dental caries has turned out to be weaker in contemporary society and this has been credited to the broad utilization of fluoride. ${ }^{31}$

\section{Environmental Risk Factors}

Several studies have confirmed that when SM bacteria have been acquired at an early age, it will mostly lead to ECC, where other factors might contribute to caries progression or prevention, such as socioeconomic status of caregivers, water fluoridation, race, number of years of education, and dental insurance coverage. ${ }^{32-34}$ Relationship among ECC and the financial status has been very much reported. Children with a background marked by dental caries, whose parents and siblings have serious dental caries, are viewed as being at high risk of having dental caries in their future. ${ }^{35,36}$ Additionally, kids involvement of financial burden influences grownup dental well-being. ${ }^{37}$ Absence of access to dental care, deficient accessibility of preventive measures, for example, water fluoridation, fluoride supplementation, and dental sealants, and the absence of information of the significance of oral well-being are contributing elements to an oral well-being decrease in young children.

\section{DIAGNOSIS}

The ECC starts with a white spot lesion on the maxillary primary incisors along the cervical third of the crown (on the edge of the gingiva). In general, the decay is first seen on the primary maxillary incisors, and the four maxillary anterior teeth are often involved concurrently. ${ }^{38}$ If the lesion is not arrested and disease continues, caries will progress to form a cavitation..$^{39,40}$ The lesion may appear on either facial or lingual surfaces or on both. ${ }^{21}$ Young children that have ECC are more susceptible to caries infection in both primary ${ }^{42}$ and permanent dentitions. ${ }^{41}$ The ECC is not only limited to oral health but is also widespread to cause several health problems. Children with ECC have a slower growth rate when compared with caries-free children, where also ECC may be affected with iron deficiency. ${ }^{42}$ Moreover, the implementation of the new expression of ECC is now in use instead of the previous terminology of bottle caries, when at least one of the following criteria is accompanied by:

- Smooth surface caries in children $\leq 3$ years

- In children between 3 and 5 years of age, any smooth surface of an anterior-posterior tooth, i.e., filled, missing (due to caries), or decayed
- The decayed, missing, and filled teeth index is equal to 4 or more for children 3 years of age, 5 for children 4 years of age, and 6 for kids 5 years of age. ${ }^{43}$

\section{MANAGEMENT}

To manage any disease, the underlying causative factor or factors must be identified. Treatment of ECC sometimes consists of restoration using microrestorative techniques and adhesive materials or by surgical removal of carious teeth. However, it is well established that recurrent caries around restorations is quite common, whereas the relapse after surgical removal of caries tooth is approximately $40 \%$ after the first year. ${ }^{21,44}$ This leads to a shift in the management from treatment to prevention of occurrence or decrease in the progression of caries. ${ }^{45-47}$

Literature has provided general approaches to be used in prevention of ECC (Flow Chart 1).

\section{Prevention of Maternal Bacterial Transmission to the Child}

This method is used as an approach in preventing carcinogenicity of feeding. The habit of feeding young children at night using nursing bottle or sippy cups will increase the risk of enamel demineralization. This habit will elevate the chance of dental caries due to flow rate of saliva and oral clearance at night, thus sugary beverage consumption at night should be stopped or at least reduced. Therefore, it is better to start very early in preventing ECC in the prebirth and perinatal periods. Newborn children whose moms have elevated amounts of SM because of untreated dental caries are at more danger of transferring these organisms to the child. ${ }^{48}$

\section{Oral Health Education}

The ultimate goal of oral health education is to prevent disease, its motivation is to encourage basic leadership for oral health reviews and to motivate proper decisions for such behaviors. The main factor contributing to caries formation is the substrate component of sugar. Consequently, most dentists shifted their concern to

Flow Chart 1: Strategies to prevent ECC

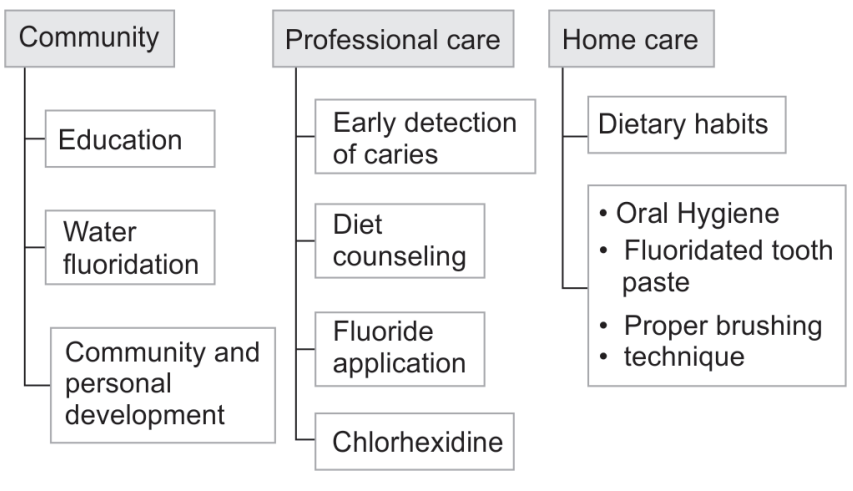


Table 1: Recommended dosage for fluoride supplementation

\begin{tabular}{llll}
\hline & \multicolumn{3}{c}{ Fluoride level of drinking water in PPM } \\
\cline { 2 - 4 } Age of Child & $<0.3$ PPM & $0.3-0.6$ PPM & $>0.6$ PPM \\
\hline Birth-6 Months & No Supplements & No Supplements & No Supplements \\
6 Months-3 Years & $0.25 \mathrm{mg}$ per day & No Supplements & No Supplements \\
$3-6$ Years & $0.50 \mathrm{mg}$ per day & $0.25 \mathrm{mg}$ per day & No Supplements \\
$6-16$ Years & $1.0 \mathrm{mg}$ per day & $0.50 \mathrm{mg}$ per day & No Supplements \\
\hline
\end{tabular}

Approved by the American Dental Association, American Academy of Pediatric Dentistry, and American Academy of Pediatrics in

1994 - Republished by OrarAnswers.com

concentrate on child diet modification and feeding habits by educating parents and caregivers. ${ }^{49,50}$ Most children do not visit the dentist until they reach 3 years of age; health care providers including physicians and nurses have a significant role in educating both parents and child, thus decreasing the disease. ${ }^{49}$ Oral health education can be carried out by providing information in the form of pamphlets, experience, or learning activities that are meant to improve oral care..$^{50}$ The AAPD has set some recommendations on expectant direction, where bottlefeeding habits can lead to avoidance of ECC. ${ }^{43}$

\section{Fluoride}

The utilization of fluorides in dentistry started in the 19th century. Fluoride is found in water so that all people ingest some fluoride every day. Water fluoridation is considered as a general well-being measure, this will aid in people in the formation of chewable tablets, washes, capsules, toothpastes, droplets, and by the dental experts in the expert use of varnishes, froths, and gels. The fluoride varnish type contains high concentration of topical fluoride, the mode of action is by increasing the concentration of fluoride on the applied surface of the tooth; this increases fluoride uptake during early stages of tooth demineralization. ${ }^{39}$

There is a worldwide agreement that normal utilization of fluoride toothpaste constitutes a foundation in youngster dental well-being. Truth be told, a worldwide overview uncovered that most specialists tended to fluoride toothpaste as the principal purpose behind the emotional decrease in caries in the 20th century. ${ }^{51}$ Furthermore, toothpaste is presumably the most promptly accessible type of fluoride and toothbrushing is an advantageous and endorsed propensity in many societies. ${ }^{52}$ Fluoride items, for example, mouth wash, dental orifice topical fluoride, and toothpaste have appeared to reduce caries between $70 \%$ and $30 \%$ of contrasted and no fluoride treatment respectively. ${ }^{53,54}$ While brushing their teeth, young children tend to swallow the toothpaste, which may intensify their experience to fluoride. The AAPD has provided certain recommendations that should be followed while prescribing fluoride toothpaste or fluoride supplements to patients in order to decrease the chance of fluoride poisoning or fluorosis while maintaining its advantages (Table 1$)^{55}$

\section{CONCLUSION}

Moreover, dental specialists need to build up the most ideal approaches to offer preventive and clinically successful care. Logical advances must obscure the boundary among dental and restorative practices. Dentists must focus on utilizing existing techniques to distinguish indications of right on time and propelled caries and give guidance on the best way to counteract and control caries in patients.

\section{ACKNOWLEDGMENT}

Author would like to thank Dr Qamar Hashem from the College of Dentistry, Princes Nourah Bint Abdulrahman University.

\section{REFERENCES}

1. Fejerskov, O.; Kidd, E. Dental caries: the disease and its clinical management. Hoboken (NJ): John Wiley \& Sons; 2009.

2. Chu CH, Fung DS, Lo EC. Dental caries status of preschool children in Hong Kong. Br Dent J 1999 Dec;187(11):616-620.

3. Stecksén-Blicks C, Sunnegårdh K, Borssén E. Caries experience and background factors in 4-year-old children: time trends 1967-2002. Caries Res 2004 Mar-Apr;38(2):149-155.

4. Bagramian RA, Garcia-Godoy F, Volpe AR. The global increase in dental caries. A pending public health crisis. Am J Dent 2009 Feb;22(1):3-8.

5. Tinanoff N. Introduction to the Early Childhood Caries Conference: initial description and current understanding. Community Dent Oral Epidemiol 1998 Oct;26(1 Suppl):5-7.

6. Dilley GJ, Dilley DH, Machen JB. Prolonged nursing habit: a profile of patients and their families. ASDC J Dent Child 1980 Mar-Apr;47(2):102-108.

7. Ismail AI, Sohn W. A systematic review of clinical diagnostic criteria of early childhood caries. J Public Health Dent 1999 Summer;59(3):171-191.

8. Schroth RJ, Brothwell DJ, Moffatt ME. Caregiver knowledge and attitudes of preschool oral health and early childhood caries (ECC). Int J Circumpolar Health 2007 Apr;66(2):153-167.

9. Drury TF, Horowitz AM, Ismail AI, Maertens MP, Rozier RG, Selwitz RH. Diagnosing and reporting early childhood caries for research purposes. A report of a workshop sponsored by 
the National Institute of Dental and Craniofacial Research, the Health Resources and Services Administration, and the Health Care Financing Administration. J Public Health Dent 1999 Summer;59(3):192-197.

10. Dentistry AAOP. Definition of early childhood caries (ECC). Reference Manual 2005-2006,2007.

11. Narvey A, Shwart L. Early childhood dental disease - what's in a name? J Can Dent Assoc 2007 Dec;73(10):929-930.

12. Harris R, Nicoll AD, Adair PM, Pine CM. Risk factors for dental caries in young children: a systematic review of the literature. Community Dent Health 2004 Mar;21(Suppl 1): 71-85.

13. Milnes AR. Description and epidemiology of nursing caries. J Public Health Dent 1996 Winter;56(1):38-50.

14. Dye BA, TanS,Smith V, Lewis BG, Barker LK, Thornton-EvansG, Eke PI, Beltrán-Aguilar ED, Horowitz AM, Li CH. Trends in oral health status: United States, 1988-1994 and 1999-2004. Vital Health Stat 112007 Apr;(248):1-92.

15. Beltran-Aguilar ED, Barker LK, Canto MT, Dye BA, Gooch BF, Griffin SO, Hyman J, Jaramillo F, Kingman A, NowjackRaymer R, et al. Surveillance for dental caries, dental sealants, tooth retention, edentulism, and enamel fluorosis--United States, 1988-1994 and 1999-2002. MMWR Surveill Summ 2005 Aug;54(3):1-44.

16. Burt, BA.; Eklund, SA. Dentistry, dental practice, and the community. St. Louis (MO): Elsevier Health Sciences; 2005.

17. Cariño KM, Shinada K, Kawaguchi Y. Early childhood caries in northern Philippines. Community Dent Oral Epidemiol 2003 Apr;31(2):81-89.

18. Thitasomakul S, Thearmontree A, Piwat S, Chankanka O, Pithpornchaiyakul W, Teanpaisan R, Madyusoh S. A longitudinal study of early childhood caries in 9- to 18-monthold Thai infants. Community Dent Oral Epidemiol 2006 Dec;34(6):429-436.

19. Skeie MS, Espelid I, Skaare AB, Gimmestad A. Caries patterns in an urban preschool population in Norway. Eur J Paediatr Dent 2005 Mar;6(1):16-22.

20. Kawashita $Y$, Kitamura M, Saito T. Early childhood caries. Int J Dent 2011 Oct;2011:725320.

21. Berkowitz RJ. Causes, treatment and prevention of early childhood caries: a microbiologic perspective. J Can Dent Assoc 2003 May;69(5):304-307.

22. Davies GN. Early childhood caries-a synopsis. Community Dent Oral Epidemiol 1998 Oct;26(1 Suppl):106-116.

23. Caufield PW, Li Y, Bromage TG. Hypoplasia-associated severe early childhood caries--a proposed definition. J Dent Res 2012 Jun;91(6):544-550.

24. van Houte J. Role of micro-organisms in caries etiology. J Dent Res 1994 Mar;73(3):672-681.

25. Caufield PW, Cutter GR, Dasanayake AP. Initial acquisition of mutans streptococci by infants: evidence for a discrete window of infectivity. J Dent Res 1993 Jan;72(1):37-45.

26. Wan AK, Seow WK, Purdie DM, Bird PS, Walsh LJ, Tudehope DI. A longitudinal study of Streptococcus mutans colonization in infants after tooth eruption. J Dent Res 2003 Jul;82(7):504-508.

27. Li Y, Caufield PW, Dasanayake AP, Wiener HW, Vermund SH. Mode of delivery and other maternal factors influence the acquisition of Streptococcus mutans in infants. J Dent Res 2005 Sep;84(9):806-811.

28. White V. Breastfeeding and the risk of early childhood caries. Evid Based Dent 2008 Feb;9(3):86-88.
29. Aarthi J, Muthu MS, Sujatha S. Cariogenic potential of milk and infant formulas: a systematic review. Eur Arch Paediatr Dent 2013 Oct;14(5):289-300.

30. Who J, Consultation FE. Diet, nutrition and the prevention of chronic diseases - Introduction. World Health Organ Tech Rep Ser 2003;916(i-viii):1-149.

31. Zero DT. Sugars - the arch criminal? Caries Res 2004 May-Jun;38(3):277-285.

32. Aida J, Ando Y, Aoyama H, Tango T, Morita M. An ecological study on the association of public dental health activities and sociodemographic characteristics with caries prevalence in Japanese 3-year-old children. Caries Res 2006 Oct;40(6):466-472.

33. Ramos-Gomez FJ, Weintraub JA, Gansky SA, Hoover CI, Featherstone JD. Bacterial, behavioral and environmental factors associated with early childhood caries. J Clin Pediatr Dent 2002 Winter;26(2):165-173.

34. Marthaler TM. Changes in dental caries 1953-2003. Caries Res 2004 May-Jun;38(3):173-181.

35. Krol DM. Dental caries, oral health, and pediatricians. Curr Probl Pediatr Adolesc Health Care 2003 Sep;33(8): 253-270.

36. Bedos C, Brodeur JM, Arpin S, Nicolau B. Dental caries experience: a two-generation study. J Dent Res 2005 Oct;84(10):931-936.

37. Poulton R, Caspi A, Milne BJ, Thomson WM, Taylor A, Sears MR, Moffitt TE. Association between children's experience of socioeconomic disadvantage and adult health: a life-course study. Lancet 2002 Nov;360(9346): 1640-1645.

38. Petti S, Cairella G, Tarsitani G. Rampant early childhood dental decay: an example from Italy. J Public Health Dent 2000 Sep;60(3):159-166.

39. Kagihara LE, Niederhauser VP, Stark M. Assessment, management, and prevention of early childhood caries. J Am Acad Nurse Pract 2009 Jan;21(1):1-10.

40. Casamassimo, PS.; Fields, HW Jr.; McTigue, DJ.; Nowak, A. Pediatric dentistry: infancy through adolescence. St. Louis (MO): Elsevier Health Sciences; 2013.

41. Peretz B, Ram D, Azo E, Efrat Y. Preschool caries as an indicator of future caries: a longitudinal study. Pediatr Dent 2003 Mar-Apr;25(2):114-118.

42. Clarke M, Locker D, Berall G, Pencharz P, Kenny DJ, Judd P. Malnourishment in a population of young children with severe early childhood caries. Pediatr Dent 2006 May-Jun; 28(3):254-259.

43. American Academy of Pediatric Dentistry. Policy on early childhood caries (ECC): classifications, consequences, and preventive strategies. Pediatric Dent 2005 Nov;27(Suppl 7): 31-33.

44. Graves CE, Berkowitz RJ, Proskin HM, Chase I, Weinstein P, Billings R. Clinical outcomes for early childhood caries: influence of aggressive dental surgery. J Dent Child (Chic) 2004 May-Jun;71(2):114-117.

45. Pitts NB. Are we ready to move from operative to nonoperative/preventive treatment of dental caries in clinical practice? Caries Res 2004 May-Jun;38(3):294-304.

46. Ismail AI. Visual and visuo-tactile detection of dental caries. J Dent Res 2004 Jun;83 Spec No C:C56-C66.

47. Pitts NB, Stamm JW. International Consensus Workshop on Caries Clinical Trials (ICW-CCT)-final consensus statements: 
agreeing where the evidence leads. J Dent Res 2004 Feb;83 Spec No C:C125-C128.

48. Milgrom P. Response to Reisine \& Douglass: psychosocial and behavioral issues in early childhood caries. Community Dent Oral Epidemiol 1998 Oct;26(1 Suppl):45-48.

49. Ng MW, Chase I. Early childhood caries: risk-based disease prevention and management. Dent Clin North Am 2013 Jan;57(1):1-16.

50. Mason, J. Concepts in dental public health. Pitman (NJ): Wolters Kluwer Health/Lippincott Williams \& Wilkins; 2010.

51. Bratthall D, Hansel-Petersson G, Sundberg H. Reasons for the caries decline: what do the experts believe? Eur
J Oral Sci 1996 Aug;104(4 (Pt 2)):416-422; discussion 423-425, 430-432.

52. Marinho VC. Evidence-based effectiveness of topical fluorides. Adv Dent Res 2008 Jul;20(1):3-7.

53. Featherstone JDB. The continuum of dental caries-evidence for a dynamic disease process. J Dent Res 2004 Jul;83 Spec No C:C39-C42.

54. Jenkins GN. Recent changes in dental caries. Br Med J (Clin Res Ed) 1985 Nov;291(6505):1297-1298.

55. Çolak H, Dülgergil CT, Dalli M, Hamidi MM. Early childhood caries update: a review of causes, diagnoses, and treatments. J Nat Sci Biol Med 2013 Jan-Jun;4(1):29-38. 